\title{
Risk factors of acute coagulation dysfunction after aneurysmal subarachnoid hemorrhage
}

\author{
Guo-Rong Chen ${ }^{1 \dagger}$, Pei-Sen Yao ${ }^{1 \dagger}$, Chu-Bin Liu ${ }^{2 \dagger}$, Huang-Cheng Shang-Guan ${ }^{1 \dagger}$, Shu-Fa Zheng ${ }^{1 *}$, Liang-Hong Yu', \\ Yuan-Xiang Lin ${ }^{1}$, Zhang-Ya Lin ${ }^{1}$ and De-Zhi Kang ${ }^{1 *}$
}

\begin{abstract}
Background: Although coagulopathy have been proved to be a contributor to a poor outcome of aneurysmal subarachnoid hemorrhage (aSAH), the risk factors for triggering coagulation abnormalities have not been studied after aneurysm clipping.
\end{abstract}

Methods: We investigated risk factors of coagulopathy and analyzed the relationship between acute coagulopathy and outcome after aneurysm clipping. The clinical data of 137 patients with ruptured CA admitted to our institution was collected and retrospectively reviewed. Patient demographic data (age, sex), smoking, alcohol use, hypertension, diabetes, Hunt-Hess grade, Fisher grade, operation time, intraoperative total infusion volume, intraoperative blood loss, intraoperative transfusion, intraoperative hemostatic drug treatment, calcium reduction (preoperative free calcium concentration-postoperative free calcium concentration) were recorded. Coagulation was assessed within 24 h. Postoperative hemorrhage and infarction, deep venous thrombosis (DVT), and mortality were analyzed.

Results: Coagulopathy was detected in a total of 51 cases (group I), while not in 86 cases (group II). Univariable analysis demonstrated that age, smoking, alcohol use, intraoperative total infusion volume, intraoperative blood loss, intraoperative transfusion, and calcium reduction $(\geq 1.2 \mathrm{mg} / \mathrm{dl})$ were related to coagulopathy. Non-conditional logistic regression analysis showed that age [OR, $1.037(95 \% \mathrm{Cl}, 1.001-1.074) ; p=0.045]$ and calcium reduction $(\geq 1.2 \mathrm{mg} / \mathrm{dl})$ [OR, $5.509(95 \% \mathrm{Cl}, 1.900-15.971) ; p=0.002]$ were considered as the risk factors for coagulopathy. Hunt-Hess grade [OR, $2.641(95 \% \mathrm{Cl}, 1.079-6.331) ; p=0.033]$ and operation time [OR, $0.107(95 \% \mathrm{Cl}, 1.012-0.928) ; p=0.043]$ were considered as the risk factors for hypocoagulopathy. There were 6 cases (11.7\%) with cerebral infarction in group I, while 6 cases $(6.98 \%)$ in group II $\left(x^{2}=0.918, p=0.338\right)$. There were 4 cases $(7.84 \%)$ with rebleeding in group I, while 5 cases (5.81\%) in group II $\left(x^{2}=0.215, p=0.643\right)$. The mortality was $9.80 \%(5 / 51)$ in group I, while $1.16 \%(1 / 86)$ in group $\|\left(x^{2}=5.708\right.$, $p=0.017)$. DVT was not detected in all cases.

Conclusions: In conclusion, age ( $\geq 65$ years) and calcium reduction ( $\geq 1.2 \mathrm{mg} / \mathrm{dl}$ ) were considered as the risk factors for coagulopathy and have been proved to be associated with higher mortality after aneurysm clipping.

Keywords: Risk factors, Coagulation dysfunction, Aneurysmal subarachnoid hemorrhage

\footnotetext{
* Correspondence: zsf2002110@163.com; kdzy99988@163.com

${ }^{\dagger}$ Guo-Rong Chen, Pei-Sen Yao, Chu-Bin Liu and Huang-Cheng Shang-Guan contributed equally to this work.

${ }^{1}$ Department of Neurosurgery, The First Affiliated Hospital of Fujian Medical

University, NO. 20 Chazhong Road, Taijiang District, Fuzhou City 350004,

Fujian, China

Full list of author information is available at the end of the article
}

(c) The Author(s). 2018 Open Access This article is distributed under the terms of the Creative Commons Attribution 4.0 International License (http://creativecommons.org/licenses/by/4.0/), which permits unrestricted use, distribution, and reproduction in any medium, provided you give appropriate credit to the original author(s) and the source, provide a link to the Creative Commons license, and indicate if changes were made. The Creative Commons Public Domain Dedication waiver (http://creativecommons.org/publicdomain/zero/1.0/) applies to the data made available in this article, unless otherwise stated. 


\section{Background}

Aneurysmal subarachnoid hemorrhage (aSAH) accounts for $3-5 \%$ of strokes, which is serious harmful to human health for its high mortality and morbidity $[1,2]$. Although neurosurgical clipping following aSAH prevents rerupture of aneurysms, reduces the mortality and cognition, and improves the Glasgow Coma Scale (GCS), neurological deficits were detected after intracranial aneurysm clipping [3-7]. And it is known that postoperative hemorrhagic or ischemic injury caused by systematic coagulopathy was closely related to these complications $[4,8,9]$.

Previous studies indicated the older patients with coagulation abnormalities are more likely to develop progressive hemorrhagic injury in traumatic brain injury (TBI) patients, including subarachnoid hemorrhage, epidural hematoma, and subdural hematoma [4]. Elevated serum fibrinogen degradation product (FDP) was associated with intracranial hemorrhage and mass effect following TBI [10]. In addition, coagulative/fibrinolytic abnormalities are the frequently cause for intracranial re-hemorrhage [11]. Hypercoagulability has been proved to be associated with cerebral arterial ischemic stroke [12]. Giroud et al. demonstrated that significant activation of the coagulation was observed in the patients with cortical infarction [13].

Furthermore, coagulopathy after TBI is a powerful predictor related to poor outcome [14], including higher in-hospital mortality, increased incidence of DVT and worse long-term functional outcomes [4, 15]. It was revealed that coagulation abnormalities were related to poor outcome in the acute stage of ruptured intracranial aneurysm [16, 17]. Ettinger found that patients with fibrinogen values over $400 \mathrm{mg} / 100 \mathrm{ml}$ shortly after subarachnoid hemorrhage had worse prognosis [18].

Although coagulopathy has been proved to be a contributor to the poor outcome of aSAH, the risk factors for triggering coagulation abnormalities have not been clarified after neurosurgical clipping. In the study, we reviewed risk factors of acute coagulopathy and analyzed the relationship between acute coagulopathy and the outcome in the aSAH patients after surgical clipping.

\section{Methods}

\section{Patients}

This prospective study was performed in the First Affiliated Hospital of Fujian Medical University. The study was approved by the ethics committee of the First Affiliated Hospital of Fujian Medical University. All patients provided written informed consent.

Patients were collected in the trial if the following conditions were met: (1) Subarachnoid hemorrhages were diagnosed by computed tomography (CT). Cerebral aneurysms were diagnosed by computerized tomography angiography (CTA) and/or digital subtraction angiography
(DSA). (2) Patients underwent a minimally invasive pterional or supraorbital keyhole approach after hemorrhage by the same surgeon. (3) Patients with preoperative coagulation abnormalities, hematological disorders, ongoing anticoagulant treatment, active alcohol or drug abuse, or malignant tumor were excluded.

\section{Assessment of coagulopathy}

We reviewed the clinical and biological correlates of coagulopathy in a large series of patients undergoing aneurysmal clipping. Coagulation meeting any one of following conditions was defined as coagulopathy: (1) fibrinogen level less than $2 \mathrm{mg} / \mathrm{dl}$ or greater than $4 \mathrm{mg} / \mathrm{dl}$; (2) prolongation or shortening of prothrombin time (PT) greater than $3 \mathrm{~s}$; (3) prolongation or shortening of activated partial thromboplastin time (APTT) greater than $10 \mathrm{~s}$; (4) prolongation or shortening of thrombin time (TT) greater than $3 \mathrm{~s}$; (5) abnormalities of D-dimmer were detected; (6) a positive test plasma protamine paracoagulation test was detected. Coagulation was assessed within $24 \mathrm{~h}$ after surgery.

\section{Analyzed factors and postoperative evaluation}

The clinical data of 137 patients with ruptured CA admitted to our institution was collected and retrospectively reviewed. Patient demographic data (age, sex), smoking, alcohol use, hypertension, diabetes, Hunt-Hess grade, Fisher grade, operation time, intraoperative total infusion volume, intraoperative blood loss, intraoperative transfusion, intraoperative hemostatic drug treatment, and calcium reduction (preoperative free calcium concentration-postoperative free calcium concentration) were recorded. Coagulation was assessed within $24 \mathrm{~h}$.

\section{Statistical analysis}

Statistical analysis was performed using SPSS version 18.0 (SPSS Inc., Chicago, IL, USA) for Windows. The chi-square $\left(\chi^{2}\right)$ test was used for categorical data, and multivariate analysis was carried out while there was statistical difference firstly analyzed by one-way ANOVA. Non-conditional logistic regression analysis was performed to identify the effects of multi factors on prognosis. A $P$ value less than 0.05 was considered as statistically significant. Basic clinical characteristics of patients are shown on Table 1. Univariable logistic regression analyses included all variables' significance level at $p<0.15$.

The following risk factors for coagulopathy were entered in the univariable analysis: age (greater than 65 years or less than 65 years), smoking, alcohol use, intraoperative total infusion volume, intraoperative blood loss, intraoperative transfusion, and calcium reduction $(\geq 1.2 \mathrm{mg} / \mathrm{dl})$. 
Table 1 Basic clinical characteristics of patients with aneurismal clipping

\begin{tabular}{|c|c|c|c|c|}
\hline $\begin{array}{l}\text { General } \\
\text { information }\end{array}$ & $\begin{array}{l}\text { Normal } 86 \\
\text { cases }\end{array}$ & $\begin{array}{l}\text { Coagulopathy } \\
51 \text { cases }\end{array}$ & $x^{2}$ value & $P$ value \\
\hline \multicolumn{5}{|l|}{ Age } \\
\hline$<65$ years & 77 & 37 & 6.612 & 0.010 \\
\hline$\geq 65$ years & 9 & 14 & & \\
\hline \multicolumn{5}{|l|}{ Sex } \\
\hline Male & 39 & 20 & 0.491 & 0.483 \\
\hline Female & 47 & 31 & & \\
\hline \multicolumn{5}{|l|}{ Smoking } \\
\hline Yes & 16 & 5 & 6.563 & 0.010 \\
\hline No & 70 & 81 & & \\
\hline \multicolumn{5}{|l|}{ Alcohol } \\
\hline Yes & 8 & 1 & 5.745 & 0.017 \\
\hline No & 78 & 85 & & \\
\hline \multicolumn{5}{|l|}{ Hypertension } \\
\hline Yes & 41 & 19 & 0.918 & 0.338 \\
\hline No & 49 & 32 & & \\
\hline \multicolumn{5}{|l|}{ Diabetes } \\
\hline Yes & 3 & 3 & 0.438 & 0.508 \\
\hline No & 83 & 48 & & \\
\hline \multicolumn{5}{|l|}{ Hunt-Hess grade } \\
\hline$|-|||$ & 73 & 42 & 0.152 & 0.697 \\
\hline IV-V & 13 & 9 & & \\
\hline \multicolumn{5}{|l|}{ Fisher grade } \\
\hline $1-2$ & 46 & 31 & 0.692 & 0.405 \\
\hline $3-4$ & 40 & 20 & & \\
\hline \multicolumn{5}{|l|}{ Operation time } \\
\hline$\leq 3 \mathrm{~h}$ & 41 & 29 & 1.082 & 0.298 \\
\hline$>3 \mathrm{~h}$ & 45 & 22 & & \\
\hline \multicolumn{5}{|c|}{ Intraoperative total infusion volume } \\
\hline$\leq 2000 \mathrm{ml}$ & 14 & 3 & 47.300 & 0.000 \\
\hline $2000-4000 \mathrm{ml}$ & 61 & 37 & & \\
\hline$\geq 4000 \mathrm{ml}$ & 11 & 11 & & \\
\hline \multicolumn{5}{|c|}{ Intraoperative blood loss } \\
\hline$\leq 300 \mathrm{ml}$ & 50 & 28 & 20.470 & 0.000 \\
\hline $300-600 \mathrm{ml}$ & 13 & 8 & & \\
\hline$\geq 600 \mathrm{ml}$ & 23 & 15 & & \\
\hline \multicolumn{5}{|c|}{ Intraoperative transfusion } \\
\hline Yes & 7 & 10 & 3.874 & 0.049 \\
\hline No & 79 & 41 & & \\
\hline \multicolumn{5}{|c|}{ Intraoperative hemostatic drug } \\
\hline Yes & 13 & 9 & 0.152 & 0.697 \\
\hline No & 73 & 42 & & \\
\hline \multicolumn{5}{|l|}{ Calcium reduction } \\
\hline$<1.20 \mathrm{mg} / \mathrm{dl}$ & 10 & 17 & 60.223 & 0.000 \\
\hline $0-1.20 \mathrm{mg} / \mathrm{dl}$ & 65 & 31 & & \\
\hline$\geq 1.20 \mathrm{mg} / \mathrm{dl}$ & 11 & 3 & & \\
\hline
\end{tabular}

\section{Results}

A consecutive series of 137 patients (range 10-86 years, mean age $53.60 \pm 11.38$ years, 59 males and 78 females) were collected between January 2012 and January 2014 in this prospective study. There were a total of 252 aneurysms: 13 located at anterior cerebral artery (ACA), 32 at the posterior communicating artery (PCoA), 68 at the middle cerebral artery (MCA), 69 at the anterior communicating artery (ACoA), 52 at the internal carotid artery (ICA), 3 at the posterior cerebral artery (PCA), 4 at the ophthalmic artery, 7 at the anterior choroidal artery, 1 at the basilar artery, and 2 at vertebral artery. A total of 33 patients were presenting with multiple aneurysms. There were 17 patients presenting with Hunt-Hess grade I, 64 with grade II, 33 with grade III, 15 with grade IV, and 7 with grade $\mathrm{V}$.

Basic clinical characteristics of patients are shown on Table 1. Coagulopathy was detected in a total of 51 cases (group I), while not in 86 cases (group II). Univariable analysis demonstrated that age, smoking, alcohol use, intraoperative total infusion volume, intraoperative blood loss, intraoperative transfusion, and calcium reduction $(\geq$ $1.2 \mathrm{mg} / \mathrm{dl}$ ) were related to coagulopathy. Non-conditional logistic regression analysis showed that age [odd ratio (OR), 1.037 (95\% confidence interval, CI, 1.001-1.074); $p$ $=0.045]$ and calcium reduction $(\geq 1.2 \mathrm{mg} / \mathrm{dl})$ [OR, 5.509 (95\% CI, 1.900-15.971); $p=0.002]$ were considered as the risk factors for coagulopathy (Table 2).

The clinical characteristics of patients with hypocoagulopathy and hypercoagulopathy are shown in Table 3. Hypocoagulopathy was detected in a total of 40 cases (subgroup I), while hypercoagulopathy in 11 cases (subgroup II). Univariable analysis demonstrated that Hunt-Hess grade, operation time, intraoperative total infusion volume, intraoperative blood loss, and calcium reduction were related to coagulopathy. Nonconditional logistic regression analysis showed that Hunt-Hess grade [OR, 2.641 (95\% CI, 1.079-6.331); $p$ $=0.033$ and operation time [OR, 0.107 (95\% CI,

Table 2 Multivariate logistic regression analysis of acute coagulopathy risk factors

\begin{tabular}{lllll}
\hline Variables & $\operatorname{Exp}(\mathrm{B})$ & \multicolumn{2}{c}{$95 \% \operatorname{Exp}(\mathrm{B})$} & $P$ value \\
\cline { 3 - 4 } & & Lower limit & Upper limit & \\
\hline Age & 1.037 & 1.001 & 1.074 & 0.045 \\
Smoking & 1.008 & 0.272 & 3.736 & 0.991 \\
Alcohol & 0.199 & 0.014 & 2.848 & 0.234 \\
Intraoperative net fluid & 1.000 & 1.000 & 1.001 & 0.571 \\
intake & & & & \\
Intraoperative blood loss & 0.999 & 0.997 & 1.001 & 0268 \\
Intraoperative transfusion & 4.163 & 0.910 & 19.032 & 0.660 \\
$\begin{array}{lllll}\text { Calcium reduction } \\
(\geq 1.2 \text { mg/dl) }\end{array}$ & 5.509 & 1.900 & 15.971 & 0.002 \\
\hline
\end{tabular}


Table 3 Basic clinical characteristics of patients with coagulation dysfunction

\begin{tabular}{|c|c|c|c|c|}
\hline General information & Hypocoagulopathy 40 cases & Hypercoagulopathy 11 cases & $x^{2}$ value & $P$ value \\
\hline \multicolumn{5}{|l|}{ Age } \\
\hline$<65$ years & 28 & 9 & \multirow[t]{2}{*}{0.605} & \multirow[t]{2}{*}{0.437} \\
\hline$\geq 65$ years & 12 & 2 & & \\
\hline \multicolumn{5}{|l|}{ Sex } \\
\hline Male & 14 & 6 & \multirow[t]{2}{*}{1.383} & \multirow[t]{2}{*}{0.240} \\
\hline Female & 26 & 5 & & \\
\hline \multicolumn{5}{|l|}{ Smoking } \\
\hline Yes & 3 & 2 & \multirow[t]{2}{*}{1.113} & \multirow[t]{2}{*}{0.291} \\
\hline No & 37 & 9 & & \\
\hline \multicolumn{5}{|l|}{ Alcohol } \\
\hline Yes & 1 & 0 & \multirow[t]{2}{*}{0.281} & \multirow[t]{2}{*}{0.596} \\
\hline No & 39 & 11 & & \\
\hline \multicolumn{5}{|l|}{ Hypertension } \\
\hline Yes & 14 & 5 & \multirow[t]{2}{*}{0.403} & \multirow[t]{2}{*}{0.525} \\
\hline No & 26 & 6 & & \\
\hline \multicolumn{5}{|l|}{ Diabetes } \\
\hline Yes & 2 & 1 & \multirow[t]{2}{*}{0.261} & \multirow[t]{2}{*}{0.610} \\
\hline No & 38 & 10 & & \\
\hline \multicolumn{5}{|l|}{ Hunt-Hess grade } \\
\hline$|-|||$ & 35 & 7 & \multirow[t]{2}{*}{3.381} & \multirow[t]{2}{*}{0.066} \\
\hline IV-V & 5 & 4 & & \\
\hline \multicolumn{5}{|l|}{ Fisher grade } \\
\hline $1-2$ & 18 & 2 & \multirow[t]{2}{*}{2.603} & \multirow[t]{2}{*}{0.107} \\
\hline $3-4$ & 22 & 9 & & \\
\hline Operation time & & & & \\
\hline$\leq 3 \mathrm{~h}$ & 14 & 9 & 5.987 & 0.014 \\
\hline$>3 \mathrm{~h}$ & 26 & 3 & & \\
\hline Intraoperative total in & & & & \\
\hline$\leq 2000 \mathrm{ml}$ & 4 & 3 & 15.321 & 0.000 \\
\hline $2000-4000 \mathrm{ml}$ & 28 & 4 & & \\
\hline$\geq 4000 \mathrm{ml}$ & 8 & 4 & & \\
\hline Intraoperative blood & & & & \\
\hline$\leq 300 \mathrm{ml}$ & 7 & 8 & 6.394 & 0.041 \\
\hline $300-600 \mathrm{ml}$ & 20 & 1 & & \\
\hline$\geq 600 \mathrm{ml}$ & 13 & 2 & & \\
\hline Intraoperative transfu & & & & \\
\hline Yes & 9 & 1 & 0.984 & 0.321 \\
\hline No & 31 & 10 & & \\
\hline Intraoperative hemos & & & & \\
\hline Yes & 6 & 3 & 0.894 & 0.344 \\
\hline No & 34 & 8 & & \\
\hline Calcium reduction & & & & \\
\hline$\leq 0 \mathrm{mg} / \mathrm{dl}$ & 2 & 1 & 39.707 & 0.000 \\
\hline $0-1.20 \mathrm{mg} / \mathrm{dl}$ & 21 & 10 & & \\
\hline$\geq 1.20 \mathrm{mg} / \mathrm{dl}$ & 17 & 0 & & \\
\hline
\end{tabular}


$1.012-0.928) ; p=0.043$ ] were considered as the risk factors for hypocoagulopathy (Table 4 ).

There were 6 cases $(11.7 \%)$ with cerebral infarction in group I, while 6 cases (6.98\%) in group II $\left(\chi^{2}=0.918, p\right.$ $=0.338)$. There were 4 cases $(7.84 \%)$ with rebleeding in group I, while 5 cases $(5.81 \%)$ in group II $\left(\chi^{2}=0.215, p\right.$ $=0.643)$. The mortality was $9.80 \%(5 / 51)$ in group I, while $1.16 \%(1 / 86)$ in group II $\left(\chi^{2}=5.708, p=0.017\right)$. DVT was not detected in all cases.

\section{Discussion}

Although neurosurgical clipping following aSAH prevents aneurysm rerupture, neurological deficit, which was related to postoperative hemorrhagic or ischemic injury, was often detected after intracranial aneurysm clipping [3-7]. Previous studies indicated that coagulopathy was positively associated with the risk of hemorrhagic or ischemic brain injury after TBI $[4,8,9,19]$. However, no studies paid attention to the risk factors for triggering coagulation abnormalities after aneurysm clipping. In the study, age, smoking, alcohol use, intraoperative total infusion volume, intraoperative blood loss, intraoperative transfusion, and calcium reduction $(\geq 1.2 \mathrm{mg} / \mathrm{dl})$ were related to coagulopathy. However, non-conditional logistic regression showed that age and calcium reduction $(\geq 1.2 \mathrm{mg} / \mathrm{dl})$ were considered as the risk factors for coagulopathy.

Operation possesses a significant risk of neurological dysfunction and death in patients $>65$ years of age with unruptured intracranial aneurysms [20] . Increasing age is associated with higher neurological morbidity and mortality after pipeline embolization of intracranial aneurysms [21]. And in the study, age more than 65 years was an independent risk factor for coagulopathy and associated with higher mortality after aneurysm clipping. Previous studies indicated that higher tissue plasminogen activator (tPA) and lower activity of plasminogen activator inhibitor (PAI) were detected in older patients. And after surgery, lower plasma concentrations of PAI-1 preoperatively leads to higher plasma levels of D-dimer in association with coagulopathy [22]. However, increasing age was not related to higher postoperative hemorrhage and infarction, which was consistent with our findings.

Table 4 Multivariate logistic regression analysis of hypocoagulopathy risk factors

\begin{tabular}{llllll}
\hline Variables & $\operatorname{Exp}(\mathrm{B})$ & \multicolumn{2}{l}{$95 \% \operatorname{Exp}(\mathrm{B})$} & \multirow{2}{*}{$P$ value } \\
\cline { 3 - 4 } & & Lower limit & Upper limit & \\
\hline Hunt-Hess grade & 2.614 & 1.079 & 6.331 & 0.033 \\
Operation time & 0.107 & 0.012 & 0.928 & 0.043 \\
Intraoperative total infusion & 1.001 & 1.000 & 1.003 & 0.054 \\
Intraoperative blood loss & 0.997 & 0.992 & 1.002 & 0.209 \\
Calcium reduction & 2.751 & 0.410 & 18.478 & 0.298 \\
\hline
\end{tabular}

Ionized calcium was defined as coagulation factors IV and played a critical role in the activity of coagulation. Hypocalcemia is a common finding in critically ill patients, especially in critically ill surgical patients, and possesses the prognostic value of poor outcome [23, 24]. Reduction of ionized calcium more than $1.2 \mathrm{mg} / \mathrm{dl}$ was associated with hypocoagulopathy and the poor outcome of aSAH patient after aneurysm clipping in our study. However, our findings indicate that calcium reduction is not associated with the hypercoagulopathy or hypocoagulopathy in the aSAH patients.

Here, it is shown that Hunt-Hess grade and operation time is considered as the risk factors for hypocoagulopathy, which has not been reported previously. We deduce that poor Hunt-Hess grade correlates with increased intracranial pressure [25], which might prevent intraoperative exposure of the cerebral aneurysm, prolong the operation time ("skin-to-skin"), and increase iatrogenic injury to brain tissue, the latter would cause the release of tissue factor, and then initiate exogenous coagulation pathway, finally lead to coagulopathy [26]. In addition, the acute brain injury following aneurysm rupture in poor condition (Hunt-Hess grade IV-V) is more serious than good condition (I-III), which will also result in the release of tissue factor. Certainly, these conclusions are drawn from a retrospective study, and it cannot be fully confirmed whether operation time is a risk factor for hypocoagulopathy; our findings should be verified in a larger prospective study.

\section{Conclusions}

In conclusion, age ( $\geq 65$ years) and calcium reduction $(\geq$ $1.2 \mathrm{mg} / \mathrm{dl}$ ) were considered as the risk factors for coagulopathy and have been proved to be associated with poor outcome after aneurismal clipping. However, postoperative coagulopathy was not related to postoperative hemorrhage and infarction. As our conclusions were drawn from a single institution experience, a larger sample is needed in order to verify our findings.

\section{Abbreviations}

ACA: Anterior cerebral artery; ACoA: Anterior communicating artery; APTT: Activated partial thromboplastin time; aSAH: Aneurysmal SAH; CT: Computed tomography; CTA: CT angiography; DSA: Digital subtraction angiography; DVT: Deep venous thrombosis; FDP: Fibrinogen degradation product; GCS: Glasgow Coma Scale; ICA: Internal carotid artery; MCA: Middle cerebral artery; PAI: Plasminogen activator inhibitor; PCA: Posterior cerebral artery; PCoA: Posterior communicating artery; PT: Prothrombin time; SAH: Subarachnoid hemorrhage; TBI: Traumatic brain injury; tPA: Tissue plasminogen activator; TT: Thrombin time

\author{
Acknowledgements \\ Not applicable. \\ Funding \\ The study was supported by the Young and Middle-aged Backbone Key \\ Research Project of National Health and Family Planning Commission of \\ Fujian Province (No. 2017-ZQN-46 to Pei-Sen Yao), Natural Science Funding \\ of Fujian Province (No. 2018J01175 to Pei-Sen Yao and No. 2018J01176 to
}


Shu-Fa Zheng), special fund for Public Health of Fujian Province Department of Finance (NO.BPB-LZY2013 to Zhang-Ya Lin), Key Clinical Specialty Discipline Construction Program of Fujian, P.R.C, and major project of Fujian Provincial Department of Science and Technology (NO.2014YZ0003 and NO. 2014 YZO1 to De-Zhi Kang).

\section{Availability of data and materials}

The datasets used and/or analyzed during the current study available from the corresponding author on reasonable request.

\section{Authors' contributions}

GRC, PSY, CBL, and HCSG conceived of the study, participated in its design, performed the statistical analysis, and drafted the manuscript. YXL, LHY, and ZYL participated in the supervision. SFZ and DZK conceived of the study and participated in its design, coordination, supervision, and revision of the manuscript. All authors read and approved the final manuscript.

\section{Ethics approval and consent to participate}

The study was approved by the ethics committee of the First Affiliated Hospital of Fujian Medical University.

\section{Consent for publication}

Not applicable.

\section{Competing interests}

The authors declare that they have no competing interests.

\section{Author details}

${ }^{1}$ Department of Neurosurgery, The First Affiliated Hospital of Fujian Medical University, NO. 20 Chazhong Road, Taijiang District, Fuzhou City 350004, Fujian, China. ${ }^{2}$ Department of Neurosurgery, The Second Affiliated Hospital of Fujian Medical University, Quanzhou City 362000, Fujian, China.

\section{Received: 15 April 2018 Accepted: 6 September 2018}

Published online: 08 October 2018

\section{References}

1. Lovelock CE, Rinkel GJ, Rothwell PM. Time trends in outcome of subarachnoid hemorrhage: population-based study and systematic review. Neurology. 2010;74(19):1494-501.

2. Connolly ES Jr, Rabinstein AA, Carhuapoma JR, Derdeyn CP, Dion J, Higashida RT, et al. Guidelines for the management of aneurysmal subarachnoid hemorrhage: a guideline for healthcare professionals from the American Heart Association/American Stroke Association. Stroke. 2012;43(6): $1711-37$.

3. Ayling OG, Ibrahim GM, Drake B, Torner JC, Macdonald RL. Operative complications and differences in outcome after clipping and coiling of ruptured intracranial aneurysms. J Neurosurg. 2015;123(3):621-8.

4. Folkerson LE, Sloan D, Cotton BA, Holcomb JB, Tomasek JS, Wade CE. Predicting progressive hemorrhagic injury from isolated traumatic brain injury and coagulation. Surgery. 2015;158(3):655-61.

5. Kang D, Yao P, Wu Z, Yu L. Ischemia changes and tolerance ratio of evoked potential monitoring in intracranial aneurysm surgery. Clin Neurol Neurosurg. 2013;115(5):552-6.

6. Wallmark S, Lundstrom E, Wikstrom J, Ronne-Engstrom E. Attention deficits after aneurysmal subarachnoid hemorrhage measured using the test of variables of attention. Stroke. 2015;46(5):1374-6.

7. Sandvei MS, Mathiesen EB, Vatten LJ, Muller TB, Lindekleiv H, Ingebrigtsen T, et al. Incidence and mortality of aneurysmal subarachnoid hemorrhage in two Norwegian cohorts, 1984-2007. Neurology. 2011;77(20):1833-9.

8. Ohman J, Servo A, Heiskanen O. Risks factors for cerebral infarction in goodgrade patients after aneurysmal subarachnoid hemorrhage and surgery: a prospective study. J Neurosurg. 1991;74(1):14-20.

9. Wong GK, Wong A, Zee BC, Poon WS, Chan MT, Gin T, et al. Cognitive outcome in acute simvastatin treatment for aneurysmal subarachnoid hemorrhage: a propensity matched analysis. J Neurol Sci. 2015;358(1-2):58-61.

10. Takanashi Y, Shinonaga M, Koh E, Naitoh M, Yamamoto I. Coagulation disorders as early predictor of brain injury. No To Shinkei. 1996;48(11): 1009-13.
11. Kurokawa Y, Hashi K, Uede T, Matsumura S, Kashiwabara S, Ishiguro M. Enlarging of intracranial hemorrhagic lesions and coagulative-fibrinolytic abnormalities in multiple-injury patients. No Shinkei Geka. 1989;17(4):335-41.

12. Ranzan J, Rotta NT. Ischemic stroke in children: a study of the associated alterations. Arq Neuropsiquiatr. 2004;62(3A):618-25.

13. Giroud M, Dutrillaux F, Lemesle M, Volot F, Lorenzini JL, Becker F, et al. Coagulation abnormalities in lacunar and cortical ischemic stroke are quite different. Neurol Res. 1998;20(1):15-8.

14. Maegele M. Coagulopathy after traumatic brain injury: incidence, pathogenesis, and treatment options. Transfusion. 2013;53(Suppl 1):28S-37S.

15. Abdelmalik PA, Boorman DW, Tracy J, Jallo J, Rincon F. Acute traumatic coagulopathy accompanying isolated traumatic brain injury is associated with worse long-term functional and cognitive outcomes. Neurocrit Care. 2016;24(3):361-70.

16. Fujita K, Tamaki N. Coagulation abnormalities in stroke--disseminated intravascular coagulation as a complication of subarachnoid hemorrhage. Rinsho Byori. 1991;39(7):729-35.

17. Touho H, Hino A, Suzuki K, Kubo T, Hirakawa K. Coagulation-fibrinolysis abnormalities in acute stage of subarachnoid hemorrhage (part 1)--with special reference to the relation between cerebral vasospasm and fibrinopeptides a and B beta. No To Shinkei. 1984;36(10):1009-14.

18. Ettinger MG. Coagulation abnormalities in subarachnoid hemorrhage. Stroke. 1970;1(3):139-42.

19. Zhang D, Gong S, Jin H, Wang J, Sheng P, Zou W, et al. Coagulation parameters and risk of progressive hemorrhagic injury after traumatic brain injury: a systematic review and meta-analysis. Biomed Res Int. 2015;2015: 261825.

20. Mahaney KB, Brown RD Jr, Meissner I, Piepgras DG, Huston J 3rd, Zhang J, et al. Age-related differences in unruptured intracranial aneurysms: 1-year outcomes. J Neurosurg. 2014;121(5):1024-38.

21. Brinjikji W, Kallmes DF, Cloft HJ, Lanzino G. Age-related outcomes following intracranial aneurysm treatment with the pipeline embolization device: a subgroup analysis of the IntrePED registry. J Neurosurg. 2016;124(6):172630.

22. Ozolina A, Strike E, Jaunalksne I, Krumina A, Bjertnaes LJ, Vanags I. PAI-1 and t-PA/PAl-1 complex potential markers of fibrinolytic bleeding after cardiac surgery employing cardiopulmonary bypass. BMC Anesthesiol. 2012;12:27.

23. Burchard KW, Gann DS, Colliton J, Forster J. Ionized calcium, parathormone, and mortality in critically ill surgical patients. Ann Surg. 1990;212(4):543-9 discussion 9-50.

24. Vivien B, Langeron O, Morell E, Devilliers C, Carli PA, Coriat P, et al. Early hypocalcemia in severe trauma. Crit Care Med. 2005;33(9):1946-52.

25. Heuer GG, Smith MJ, Elliott JP, Winn HR, LeRoux PD. Relationship between intracranial pressure and other clinical variables in patients with aneurysmal subarachnoid hemorrhage. J Neurosurg. 2004;101(3):408-16.

26. Broze GJ Jr. Tissue factor pathway inhibitor and the revised theory of coagulation. Annu Rev Med. 1995;46:103-12.

Ready to submit your research? Choose BMC and benefit from:

- fast, convenient online submission

- thorough peer review by experienced researchers in your field

- rapid publication on acceptance

- support for research data, including large and complex data types

- gold Open Access which fosters wider collaboration and increased citations

- maximum visibility for your research: over $100 \mathrm{M}$ website views per year

At BMC, research is always in progress.

Learn more biomedcentral.com/submissions 